\title{
POPULISMO, DEMOCRACIA Y MOVIMIENTOS POPULARES: LA REIVINDICACIÓN DEL DERECHO AL TRABAJO EN EL CASO DE LAS EMPRESAS RECUPERADAS POR LOS TRABAJADORES
}

\author{
Eduardo Esteban Magoja \\ Universidad de Buenos Aires, Argentina
}

http://dx.doi.org/10.5209/NOMA.55528

\begin{abstract}
Resumen: El propósito de este trabajo es defender la importancia del populismo en la conformación de la democracia argentina en los últimos años. En primer lugar, siguiendo a Laclau veremos cómo el populismo, lejos de significar una anormalidad política, es una forma de unificar las demandas dispersas bajo una misma identidad que contribuye en la construcción del campo político. En segundo lugar, de acuerdo con esta línea de pensamiento, destacaremos en particular cómo el movimiento de las empresas recuperadas por los trabajadores (ERT) es, al igual que todo movimiento popular, un engranaje central en la construcción del Estado democrático de derecho.
\end{abstract}

Palabras clave: populismo, democracia, derecho al trabajo, empresas recuperadas

\begin{abstract}
The purpose of this paper is to defend the importance of populism in the conformation of Argentine democracy in recent years. Firstly, following Laclau we will see how populism, far from signifying a political anomaly, is a way of unifying the dispersed demands under the same identity, which contributes in the construction of the political field. Secondly, according to this line of thought, we will highlight in particular how the movement of worker-recovered companies (WRC) is, like all popular movements, a central gear in the construction of the democratic state of law.
\end{abstract}

Keywords: populism, democracy, right to work, worker-recovered companies

\section{Introducción}

Heidegger en Introducción a la metafísica formuló una sentencia que pasó a la historia y es muy conocida dentro de la comunidad filosófica: la expresión "filosofía cristiana" es un contrasentido, un oxímoron. es como decir "hierro de madera"'. Más allá de que Heidegger tenga razón podemos trasladar la idea a la expresión "pensamiento populista" y preguntarnos si no se trata de una oración constituida por dos palabras que tienen un significado contradictorio $u$ opuesto. Pero la cuestión no termina allí. Este problema nos conduce a plantearnos aún más interrogantes: ¿es posible hablar de un pensamiento populista?; si es así, ¿̇dónde está tal pensamiento? Incluso, todos estos interrogantes se condensan todavía en un más básico: ¿qué es el populismo?

Hablar de populismo implica sumergirse en una serie de discusiones filosóficas acerca de su significado, su carácter, su rol en el escenario político. Esto es natural, pues populismo es un término vago y ambiguo que puede significar varias cosas. Incluso cuando se habla de populismo se suele hacer referencia por lo general a un término que

\footnotetext{
1 Heidegger (2001: 17).
} 
carga con una connotación peyorativa. Esta concepción negativa está ligada -explica Laclau (2005a)- "a una concepción tecnocrática del poder según la cual sólo los expertos deben determinar las fórmulas que van a organizar la vida de la comunidad".

Ahora bien, en este trabajo se buscará defender la importancia del populismo en la conformación de la democracia. A tales fines, el trabajo se dividirá en dos partes concatenadas. Siguiendo a Laclau, veremos cómo el populismo, lejos de significar una anormalidad o una desviación política, es una forma de unificar las demandas dispersas bajo una misma identidad que contribuye a la construcción de lo político. En segundo lugar, destacaremos cómo los movimientos populares son un engranaje central en la construcción del Estado democrático de derecho. Este punto será desarrollado mediante el análisis de la reivindicación del derecho al trabajo realizada por el movimiento de las empresas recuperadas por los trabajadores (en adelante ERT) luego de la crisis económica argentina del año 2001.

\section{Populismo: unas breves palabras sobre la propuesta de Laclau}

La pregunta que estructura esta sección puede formularse en los siguientes términos: ¿qqué es lo que se quiere decir cuando se habla de populismo? Si bien los desarrollos teóricos acerca de esta cuestión son amplios y prometedores ${ }^{2}$, no resultaría exagerado decir que Laclau fue uno de los autores de las últimas décadas que abordó el tema con precisión y profundidad en su obra La razón populista de $2005^{3}$.

Laclau advierte que el populismo es un fenómeno político que suele ser denigrado y denostado, que carga con una fuerte connotación negativa. Existe una tendencia que lo tilda de marginal, carente de racionalidad, ambiguo y sumamente vago; también se lo caracteriza por el vacío ideológico y la transitoriedad. Es por esta razón que el populismo es considerado en términos de anormalidad y desviación política.

A diferencia de esta lectura, Laclau va a sostener que el populismo en realidad siempre está presente en la estructuración de la vida política: "es una forma de pensar las identidades sociales, un modo de articular demandas dispersas, una manera de construir lo político"4. Su propósito es en última instancia determinar su differentia specifica y rescatar la positividad del fenómeno. Al respecto, cabe señalar que el populismo es entendido como una lógica política que no se reduce a ningún tipo especial de movimiento social. De hecho, Laclau (2005b: 219) dice de

\footnotetext{
2 Así por ejemplo, Zanatta (2015), entre muchos otros.

3 El estudio de Laclau acerca del populismo se remontan tal lejos como a su obra Política e ideología en la teoría marxista de 1978. También, ver Laclau (2005c).

${ }^{4}$ Laclau (2005b).
} 
forma expresa que no está interesado en brindar una definición rígida, sino establecer un área de variaciones dentro de la cual se inscriben una pluralidad de fenómenos y pueden ser descriptas diversas tendencias.

El profesor de la Universidad de Essex explica que el populismo es una forma de constituir la unidad de un grupo ${ }^{5}$. Esta constitución es denominada "práctica articulatoria populista". Es aquí donde entra en juego el argumento medular del autor: la articulación populista está constituida por demandas democráticas. Esta clase de demandas constituye algún tipo de exclusión y es la unidad más pequeña al momento de analizar la cuestión de la identidad popular. Diríamos que son los elementos más básicos, el equivalente al átomo en la física.

La condición de posibilidad de la existencia de todo grupo que se proclame popular es el conjunto de demandas insatisfechas y heterogéneas que no son reconocidas por el sistema. Hay un reclamo por parte de un sector de la población que no tiene lugar dentro del orden existente. Se trata, para decirlo con las propias palabras de Laclau (2005b: 304), de "la parte sin parte": el pueblo que, al mismo tiempo que es parte, exige ser todo. Entonces, mientras las demandas permanecen aisladas son democráticas, pero al ir creciendo y encontrando una articulación equivalencial, forman una subjetividad social más amplia y terminan por constituirse en demandas populares.

Cuando se intensifican las demandas insatisfechas y se consolida una unidad de identidad se separa cada vez más la brecha entre el orden institucional (que debería dar respuestas, pero no lo hace) y el pueblo. Esto establecerá una frontera antagónica, es decir una división interna que separa a la sociedad en dos campos: un "nosotros-pueblo" y un "ellos-poder" que se expresa como un "otro". Esta última parte, que aparece bajo múltiples rostros (monarquías, terratenientes, militares, capitalistas, etc.) cumple un rol clave en la constitución de la identidad popular, pues permite la cohesión del grupo demandante y fortalece sus vínculos compartidos que se establecen a partir de las demandas insatisfechas ${ }^{6}$. Sin embargo, para la constitución de la identidad es necesario un paso más. Tomando prestadas las palabras de Retamozo (2006: 227) en "estas identidades es fundamental la producción de ciertos significados densos que permiten anclar el sentido en la formación de la cadena discursiva". En efecto, como las demandas son heterogéneas, dispersas y recogen una pluralidad de intereses, no sería posible la representación del todo: ello sólo es posible si portan un significante que sea vacío.

\footnotetext{
5 Cf. Laclau (2005b: 97 y ss.).

6 Así pues, Aboy Carlés (2013: 22) destaca que, si bien el mundo popular no puede nunca definirse como lo opuesto puro al poder, "la oposición al poder es un elemento central en la constitución de la solidaridad popular".
} 
El significante vacío no debe ser confundido con una abstracción. Es más bien una suerte de polo unificador que articula todas las demandas sin remitir a ninguna de ellas en particular: condensa las demandas heterogéneas sin disolver ninguna de ellas. En relación con este punto, Laclau (2005b: 125) dice que "cualquier identidad popular requiere ser condensada, como sabemos, en torno a algunos significantes (palabras, imágenes) que se refieren a la cadena equivalencial como totalidad" y esa identidad popular "se vuelve cada vez más plena desde un punto de vista extensivo, ya que representa una cadena siempre mayor de demandas; pero se vuelve intensivamente más pobre, porque débe despojarse de contenidos particulares a fin de abarcar demandas sociales que son totalmente heterogéneas entre sí". En este contexto, por cierto, el nombre ocupa un lugar privilegiado dentro de la fundamentación de la identidad colectiva. La unidad del conjunto equivalencial, dice Laclau (2005b: 139), "depende enteramente de la productividad social del nombre". Siguiendo a Žižek, va a decir que "el punto nodal (point de capiton) cuyo nombre genera la unidad de una formación discursiva -el objeto a de Lacan- no tiene ninguna identidad positiva propia" 7 , sino que es un significante puro que satisface la función de fijación nodal.

Existen dos consecuencias interesantes de la unidad del objeto al ser nombrado: en primer lugar, el nombre va a "ejercer una atracción irresistible sobre cualquier demanda vivida como insatisfecha y, como tal, como excesiva y heterogénea con respecto al marco simbólico existente"; en segundo lugar, el nombre, como significante vacío, "es incapaz de determinar qué tipo de demandas entran en la cadena equivalencial" 8. Por lo demás, resulta importante destacar que el nombre cumple su función en la medida de que esté investido de afecto, de una atracción afectiva.

Queda claro que de acuerdo con Laclau existen ciertas dimensiones que caracterizan el populismo: la aparición de demandas insatisfechas, la conformación de una cadena de equivalencias constituidas por tales demandas, la formación de una frontera antagónica, el significante vacío, el nombre y el afecto.

\section{La emergencia del movimiento de las ERT en Argentina}

Haber dejado a un lado toda connotación negativa del populismo y los movimientos populares ha sido el primer paso para comenzar a destacar su valor en la construcción del Estado democrático de derecho. Ahora, tras haber establecido un terreno teórico firme sobre la carga positiva del fenómeno, podemos detenernos a analizar el movimiento de las ERT y explorar su función en el fortalecimiento del

\footnotetext{
7 Laclau (2005b: 134).

8 Laclau (2005b: 140).
} 
derecho humano básico al trabajo. Sin embargo, la explicación no se puede dar de un plumazo, sino que requiere que realicemos, como preludio, una breve y rápida consideración de corte histórico.

Después de la más sangrienta dictadura militar y con la recuperación de la democracia en 1983, la promoción y la protección de los derechos humanos ocuparon un lugar protagónico en la agenda política argentina. La promulgación de la Constitución de 1994 marcó un rumbo firme con la incorporación al texto constitucional de la Declaración Americana de los Derechos y Deberes del Hombre (1948), la Declaración Universal de Derechos Humanos (1948), la Convención Americana sobre Derechos Humanos (1969) y el Pacto Internacional de Derechos Económicos, Sociales y Culturales (1966), entre muchos otros. En la última década, el Estado argentino continuó afianzando su compromiso con la comunidad internacional. Esto se puede ver con claridad, por ejemplo, en las decisiones adoptadas por la Corte Suprema de Justicia de la Nación en materia de delitos de lesa humanidad9 y en la reciente adhesión de Argentina en el 2016 a la Declaración de Chapultepec sobre la Defensa de la Libertad de Expresión (1994).

Ahora bien, sin negar su valor e importancia, los avances legislativos mencionados no significaron que los derechos básicos hayan sido garantizados y respetados en su plenitud por parte de los poderes públicos de turno. El reconocimiento del derecho en la letra de la ley no siempre alcanza. Tampoco son suficientes las vías institucionales que el Estado pone al alcance de los particulares para que puedan reparar una situación de vulneración. Esto es algo que no se puede negar; es el problema entre la brecha que existe entre el deber ser de la norma y el ser de la vida social en concreto. Es por esta razón que las injusticias muchas veces exigen que los afectados adopten medidas extrajurídicas eficaces que rompan o resistan cualquier modelo de dominación que pretendiese obturar la vida misma.

Tal situación se puede percibir en el contexto histórico de los 90, cuando los movimientos populares se alzaron como fuerzas contra-hegemónicas con el fin de asegurar y defender derechos básicos. Basta mencionar los piqueteros como actores políticos centrales de resistencia contra la creciente pérdida de los puestos de trabajo y el incremento de la riqueza en unas pocas manos, frutos del modelo económico neoliberal. Los piqueteros son una fuerza que se construyeron por fuera de las estructuras sindicales tradicionales y que instalaron la lucha a través de los cortes de rutas. La primera manifestación de este movimiento se produjo en 1996 en la ciudad neuquina de Cutral-Có, con cortes en la

\footnotetext{
9 En este sentido, resulta emblemático el fallo "Simón, Julio Héctor y otros s/ privación ilegítima de la libertad" de la Corte Suprema de Justicia de la Nación, en el cual se declaró el 14 de junio de 2005 la inconstitucionalidad de las leyes de Punto Final (1986) y Obediencia Debida (1987).
} 
ruta nacional $\mathrm{n}^{\circ} 22$ como protesta contra los masivos despidos realizados por YPF (Yacimientos Petrolíferos Fiscales). Esta modalidad al poco tiempo se fue extendiendo en diversas partes del país y dio lugar a los primeros Movimientos de Trabajadores Desocupados.

Sin embargo, como no podía ser de otro modo, la emergencia de los movimientos populistas en los 90 rara vez fue recibida con simpatía por el gobierno de turno y por eso tuvo que enfrentarse con varios obstáculos. Entre ellos se destaca uno de carácter lingüístico. En efecto, en ese momento la percepción del populismo había cambiado por completo de significado. Se había producido, como explica Dussel (2015: 224) "un deslizamiento semántico, una redefinición políticoestratégica del término". El populismo empezó a significar toda medida o movimiento popular que se opusiera al fenómeno de la globalización que justificara la privatización de los bienes públicos del Estado, la apertura del mercado a productos de países poderosos y negara las necesidades de la población. Así pues, todos los movimientos populares que se oponían a ese proyecto neoliberal eran tildados de populistas con un claro sentido peyorativo. Los grupos dominantes utilizaban el término casi como un insulto, un enunciado descalificador para intentar desplazar a sus oponentes del campo político. Esta tarea, por cierto, no le fue tan fácil. Las decisiones que aspiraban a estructurar el mercado de acuerdo con los lineamientos del neoliberalismo encontraron un foco de resistencia y lucha en los movimientos populares. Éstos se alzaron como pueblo, como bloque social de los oprimidos y excluidos, y expresaron su disenso. Hubo una toma de consciencia de las necesidades materiales incumplidas que hizo que el pueblo comenzara a organizarse en los movimientos sociales.

Los movimientos populistas también tuvieron su fuerte protagonismo en la primera década del año 2000. En efecto, con el correr del tiempo lás políticas económicas de los 90 mostraron su costado más nocivo en el 2001 y dieron inicio a uno de los peores períodos de crisis económica que tuvo que atravesar Argentina. En este escenario, uno de los movimientos que alzó su voz contra la situación miserable a la que se había llegado fue el de las ERT10. Tal como fuera propuesto al comienzo de este trabajo, nos ocuparemos en analizarlo con mayor atención.

Las ERT aparecieron como una clara respuesta a las consecuencias que había dejado el modelo neoliberal11. La quiebra constante de las empresas y los niveles de desocupación crecían a niveles alarmantes. Ante esta situación, los trabajadores se autoconvocaron, se

\footnotetext{
10 Naturalmente, este fenómeno no se limita a Argentina, sino que caracteriza a todo el contexto latinoamericano. Al respecto, resulta muy interesante el libro editado por Soul, Maçaira, Guevara, et al. (2012) que lleva por título El mundo del trabajo en América Latina: tendencias y resistencias.

11 Si bien las ERT tuvieron SU mayor protagonismo a partir del año 2001, existen antecedentes en la década del 90.
} 
reorganizaron y asumieron el mando de la empresa con el fin de continuar su explotación. Veían a esta actitud como la única forma que les permitía conservar sus puestos de trabajo y evitar el desempleo. Se puede decir, siguiendo a Laclau, que sus demandas insatisfechas se convirtieron en demandas populares y se aglutinaron en un grupo homogéneo en el que los intereses de los particulares se articularon bajo un significante vacío. El nombre "empresas recuperadas" -el cual por cierto utilizaron y continúan utilizando los propios trabajadores para identificarse- sirvió para fusionar las individualidades y constituir una identidad colectiva que reclamaba la satisfacción de derechos frente al poder. Está claro, entonces, que las ERT se inscriben dentro de la lógica política del populismo, como una de sus tantas manifestaciones.

Si tuviéramos que decir en pocas palabras qué son las ERT, podríamos definirlas, siguiendo a Ruggeri (2009: 19), como "un proceso social y económico que presupone la existencia de una empresa anterior, que funcionaba bajo el molde de una empresa capitalista tradicional (inclusive, en algunos casos, bajo formas legales cooperativistas) y cuyo proceso de quiebra, vaciamiento o inviabilidad llevó a los trabajadores a una lucha por su puesta en marcha bajo formas autogestionadas".

En la actualidad existen alrededor de 367 empresas recuperadas, que ocupan a 15.948 trabajadores $^{12}$. El $32,43 \%$ se encuentran en el Gran Buenos Aires, el $19,07 \%$ en la Ciudad Autónoma de Buenos Aires, el $14,71 \%$ en el interior de la Provincia de Buenos Aires y el resto en las demás provincias del país. En cuanto a las actividades que realizan, los tres rubros más representativos son el metalúrgico (con un 19,62\%), el alimenticio $(13,62 \%)$ y el gráfico $(13,62 \%)$, y luego le siguen en menor proporción otros como, por ejemplo, el textil $(7,63 \%)$, el gastronómico $(6,81 \%)$ y el de industria de carne $(6,81 \%)$.

La gran mayoría de las ERT adoptaron la forma de cooperativas de trabajo ${ }^{13}$. Esta actitud no fue azarosa, sino que encuentra su causa en la reforma que tuvo la Ley de Concursos y Quiebras (Ley 24.522) en el 2002. En efecto, en virtud del artículo 190 los trabajadores, agrupados como cooperativa de trabajo, tenían la posibilidad de continuar con la explotación de la empresa quebrada ${ }^{14}$.

La conformación de una cooperativa de trabajo era la única estrategia jurídica que estaba al alcance de los trabajadores para obtener personería jurídica. Si bien no resolvió todos los problemas, la adopción de esta figura les permitió quedar dentro de un marco normativo que

\footnotetext{
12 Los datos han sido extraídos del informe "Las empresas recuperadas por los trabajadores en los comienzos del gobierno de Mauricio Macri" (estado de la situación a marzo de 2016), elaborado por el Programa Facultad Abierta de la Facultad de Filosofía y Letras de la Universidad de Buenos Aires.

13 Cf. Ruggeri (2009: 18). En relación con el tema de las cooperativas de trabajo y las empresas recuperadas ver en especial la obra de Tevez (2010).

14 La ley que regula las cooperativas de trabajo es la Ley 20.337.
} 
regulara su actividad. Así, la unidad de los trabajadores pudo tener representación frente a los organismos gubernamentales y las instancias judiciales, adquirir subsidios, préstamos y seguros, facturar y comercializar de acuerdo con las leyes del mercado ${ }^{15}$.

Existe otro aspecto positivo con respecto a la constitución de las ERT en cooperativas. Una cooperativa es, como dice la Organización Internacional del Trabajo, "una asociación autónoma de personas unidas voluntariamente para satisfacer sus necesidades y aspiraciones económicas, sociales y culturales en común a través de una empresa de propiedad conjunta, y de gestión democrática"16. En la Declaración de Identidad Cooperativa de la Alianza Cooperativa Internacional (pronunciada en Manchester en 1995) se remarcó su contenido axiológico, diciendo que "las cooperativas se basan en los valores de ayuda mutua, responsabilidad, democracia, igualdad, equidad y solidaridad". Con respecto a los miembros de las cooperativas, se señáló además "los valores éticos de honestidad, transparencia, responsabilidad social y preocupación por los demás". Así pues, a diferencia de una empresa tradicional, presenta varios aspectos democráticos en lo que refiere a la organización, la distribución del salario, la toma de decisiones, el control y la producción ${ }^{17}$.

Esto nos lleva a señalar una cuestión muy interesante relacionada con la naturaleza de las ERT: ellas rompen la lógica según la cual la dirección de la empresa corresponde al empresario. Los trabajadores no ejercen la labor productiva bajo el gobierno de otro y son dueños de la fuerza vital que mueve a la empresa. El binomio empresario/trabajador no tiene aquí ninguna razón de ser. O, como dice Tevez (2010: 120), "por definición no puede hablarse en ella de la existencia de empleados, pues no los hay" 18. La cooperativa excluye la idea del "trabajador dependiente", pues sus integrantes y socios son los trabajadores. Así se ha pronunciado la Corte Suprema de Justicia de la Nación en el fallo "Cuccioletti c/ Cooperativa de Trabajo 12 de enero Ltda." de 1969, en donde dijo que "si se mantiene el sistema de contratar trabajadores no socios, las cooperativas de trabajo dejarían de llenar el fin de su creación, pues no cabe duda que la esencia de las mismas, radica en la exclusiva labor de los asociados, salvo casos en que se justifique la excepción". Este principio fue confirmado nuevamente por el Máximo Tribunal en el precedente "Lago Castro, Andrés M. C/Cooperativa

\footnotetext{
${ }_{15}$ Con respecto a las ventajas de constituirse en cooperativas, ver Vieta (2009: 98-99).

16 Recomendación $n^{\circ} 193$ de 2002.

17 De hecho, en esa Declaración de Identidad Cooperativa se destacaron como principios por medio de los cuales las cooperativas efectivizan sus valores: la adhesión abierta y voluntaria, el control democrático de los socios, la participación económica de los socios, el cooperación entre cooperativas y el compromiso con la comunidad. 18 Sin embargo, sobre este punto la jurisprudencia no es unánime. Existen posiciones divergentes en cuanto a la (in)existencia de una relación laboral. Al respecto, ver Tevez (2010: 113 y ss.).
} 
Nueva Salvia Ltda. y otros" de 2009, cuando señaló que "el vínculo jurídico entre el asociado y la cooperativa de trabajo es de naturaleza asociativa y está exento, por lo tanto, de toda connotación de dependencia".

\section{Los aportes jurídicos de las ERT en la Ley de Concursos y Quiebras}

La fuerza del movimiento de las ERT ha dejado su impronta en el ordenamiento jurídico. La lucha se ve plasmada en la consecución de triunfos, es decir, reconocimiento de derechos. Sin embargo, estas conquistas llevaron mucho tiempo. En efecto, si miramos el desarrollo del proceso recién en el 2002 se empezó a ver la aparición de normas que tutelaban los intereses de los trabajadores. En esa fecha, la Ley 25.589 modificó, entre otros, el artículo 190 de la Ley de Concursos y Quiebras -el cual hemos mencionado en el apartado anterior-, estableciendo cambios que impactaron directamente sobre las ERT. La primera parte del nuevo artículo quedó redactada así:

En toda quiebra, aun las comprendidas en el artículo precedente, el síndico debe informar al juez dentro de los veinte (20) días corridos contados a partir de la aceptación del cargo, sobre la posibilidad excepcional de continuar con la explotación de la empresa del fallido o de alguno de sus establecimientos y la conveniencia de enajenarlos en marcha. En la continuidad de la empresa se tomará en consideración el pedido formal de los trabajadores en relación de dependencia que representen las dos terceras partes del personal en actividad o de los acreedores laborales quienes deberán actuar en el período de continuidad bajo la forma de una cooperativa de trabajo.

La sanción de esta norma significó un avance muy importante para los trabajadores. Intentó brindar en momentos de plena crisis una solución a aquellos que querían preservar sus puestos de trabajo. Sin embargo, faltaba todavía una normativa que supiera entender las características especiales de ese fenómeno. Los constantes reclamos de los trabajadores y los actores políticos que tuvieron algún vínculo con las ERT agudizaron el conflicto y dieron cuenta de las numerosas cuestiones que todavía se debían regular. Esto se fue desplegando de a poco, de forma lenta y gradual, aunque con constancia y firmeza. Así, en el 2006 la Ley 26.086 estableció nuevas modificaciones que, si bien no incidieron directamente en la situación de las empresas recuperadas, sí lo hicieron sobre los trabajadores y sus créditos ${ }^{19}$. En realidad, no será hasta que se sancione la Ley 26.684 en el 2011 para que se introduzcan modificaciones sustanciales con repercusiones directas sobre las ERT.

Con esta reforma de la Ley de Concursos y Quiebras se establecieron

19 Al respecto, ver Feser \& Lazarini (2011: 290-291). 
grandes cambios que hasta ese momento no estaban contemplados 20 . Nos interesa destacar aquí los siguientes temas que quedaron regulados en la actual redacción de la ley ${ }^{21}$. En primer lugar, la ley establece la incorporación de los trabajadores en el comité de control que se constituye tras la apertura del concurso. De acuerdo con el artículo 14 inciso 13, el comité estará integrado por los tres acreedores quirografarios de mayor monto denunciados por el deudor y un representante de los trabajadores de la concursada, que será elegido por los trabajadores. La composición varía al momento de ser dictada la resolución de categorización. Así, el artículo 42 establece que "el juez designará a los nuevos integrantes del comité de control, el cual quedará conformado como mínimo por un (1) acreedor por cada categoría de las establecidas, debiendo integran el mismo necesariamente el acreedor de mayor monto dentro de la categoría y por dos (2) nuevos representantes de los trabajadores de la concursada, elegidos por los trabajadores, que se incorporarán al ya electo conforme el artículo 14, inciso 13". Como se puede ver, pues, el número de representantes de los trabajadores asciende a tres ${ }^{22}$ y se propone que los empleados cuenten con la debida información del trámite del concurso.

En segundo lugar, el artículo 48 bis regula la posibilidad de que la cooperativa de trabajo, incluso en formación, pueda adquirir la empresa en el marco del denominado cramdown o "salvataje de empresa"23. Al respecto, vale señalar que el cramdown es, como explica Dasso (1994: 1228), "un sistema de propuesta de acuerdo preventivo por tercero, quien en caso de obtener la conformidad de los acreedores, adquiere la empresa concursada. Implica la sustitución del empresario cesante que en subsidio de su fracaso en la obtención del

20 De hecho, algunos autores hablan de nuevos paradigmas concursales en la nueva ley. Así por ejemplo, Vítolo (2011: 973 y ss.) sostiene que la gran novedad es el cambio de dos principios: el de "conservación de la empresa en crisis" por el de "conservación de la actividad productiva" y el de "protección de las relaciones laborales y el empleo" por el de "fomento de la reconversión de las relaciones laborales en formas asociativas independientes para el rescate de empresas en crisis".

21 No es el espíritu de nuestro trabajo detenernos en todas las cuestiones técnicas jurídicas de la reforma. Al respecto, pueden verse los trabajos de Tévez (2011), Gebhardt (2011), entre otros.

22 Se ha discutido en la jurisprudencia si en la nueva conformación del comité de control se mantiene el representante de los trabajadores o cesan sus funciones. El Juzgado de Primera Instancia en lo Civil n ${ }^{\circ} 1$ de Cippolletti, en los autos "Transmarítima Cruz del Sud S.A. s/concurso preventivo (resolución del 25/10/2011), sostuvo que de acuerdo con la ley únicamente cesan todos los representantes de los acreedores y, por eso, el comité queda conformado por tres representantes de los trabajadores. Ver al respecto el comentario al fallo de Tropeano (2012).

23 La posibilidad de que las cooperativas participen del cramdown ya había sido aceptada por la jurisprudencia. Así sucedió en el caso "Franinno Industrias Metalúrgicas S.A. s/concurso" del Juzgado de Procesos Concursales y Registro $n^{\circ} 3$ de Mendoza (resolución del 25/09/1998). 
acuerdo es sustituido por otro empresario que se supone en mejor situación para la continuación de la actividad de la empresa"24.

En tercer lugar, el artículo 190, que -recordemos- permitía que los trabajadores organizados como cooperativa pudieran continuar con la explotación de la empresa ${ }^{25}$, fue complementado con la introducción del artículo 191 bis. Se dispuso que "en toda quiebra que se haya dispuesto la continuidad de la explotación de la empresa o de alguno de sus establecimientos por parte de las dos terceras partes del personal en actividad $O$ de tos acreedores taborales, organizados en cooperativas, incluso en formación, el Estado deberá brindarle la asistencia técnica necesaria para seguir adelante con el giro de los negocios".

En cuarto lugar, el artículo 195 dispone que, en caso de continuación de la empresa, los acreedores hipotecarios o prendarios no pueden en determinadas circunstancias ejecutar los bienes necesarios para la explotación ${ }^{26}$. Pero esto no es todo. El artículo en cuestión también establece que el juez de la quiebra podrá, por decisión fundada y a pedido de la cooperativa de trabajadores, suspender las ejecuciones hipotecarias y/o prendarias por un plazo de hasta dos años.

En quinto lugar, el artículo 203 bis, cuyas disposiciones encuentran antecedentes en la jurisprudencia27, establece que "los trabajadores reunidos en cooperativa de trabajo están habilitados para solicitar la adquisición [...] y podrán hacer valer en ese procedimiento la compensación con los créditos que le asisten a los trabajadores de la fallida" 28. La norma dispone a su vez que, a los fines de la compensación, el monto de las indemnizaciones será calculado de

24 Sobre el tema, ver también Mosso (1998).

25 También el artículo 190 sufrió una mínima modificación en su redacción. Resulta interesante ver que ya no se habla más de "la posibilidad excepcional" de continuar con la empresa.

26 El artículo 195 fija con claridad los supuestos: primero, "cuando los créditos no se hallen vencidos a la fecha de la declaración y el síndico satisfaga las obligaciones posteriores en tiempo debido"; segundo, "cuando los créditos se hallen vencidos a la fecha de la declaración, mientras no cuenten con resolución firme que acredite su calidad de acreedor hipotecario o prendario; tercero, "cuando exista conformidad del acreedor hipotecario o prendario para la suspensión de la ejecución".

27 Basta aquí mencionar tos casos "Comercio y Justicia Editores S.A. -Concurso Preventivo- Hoy Quiebra" del Juzgado Civil de ta $7^{\circ}$ Nominación de Córdoba (Sentencia $n^{\circ}$ 134, 21/08/2003) y "Salvia S.A. s/quiebra s/incidente de realización de bienes", del Juzgado Nacional de Primera Instancia en lo Comercial $n^{\circ} 8$, Secretaria $n^{\circ}$ 15 (resoluciones del 5/7/00 y del 11/08/2003).

28 Muy recientemente, en un fallo del 5 de julio de 2016, la Cámara Nacional de Apelaciones en lo Comercial (Sala B) dispuso, en los autos "Ramos Hermanos S.A. s/ quiebra s/ incidente de enajenación de la empresa en marcha", la aplicación del artículo 203 bis de la Ley de Concursos y Quiebras. Los jueces dejaron en claro que "la finalidad del ordenamiento concursal es la de privilegiar la conservación del emprendimiento en manos de los trabajadores, para lo cual deben computarse la totalidad de los créditos que ellos detentan". 
acuerdo con lo establecido en el artículo 245 de la Ley 20.744 (Ley de Contrato de Trabajo), los estatutos especiales, convenios colectivos o contratos individuales. La elección entre uno $u$ otro se establece en función de cuál resultare más favorable para los trabajadores.

El último artículo que nos interesa mencionar es el 205, cuyo texto habilita a la cooperativa a adquirir la empresa, sea en caso de licitación o subasta. En este sentido, el inciso 8 del artículo deja en claro que el juez debe asegurar la fuente de trabajo. Así, dispone que el magistrado "ponderará especialmente el aseguramiento de la continuidad de la explotación empresaria, mediante el plan de empresa pertinente y la magnitud de la planta de personal que se mantiene en actividad como tutela efectiva de la fuente de trabajo". Esto es ni más ni menos que privilegiar el proyecto de los trabajadores reunidos en cooperativa. El espíritu de la norma es que los trabajadores tengan ese privilegio a los fines de adquirir la empresa en virtud de que fueron ellos quienes se encargaron de continuar su explotación.

A partir de lo expuesto hasta aquí, se puede decir que la reforma legislativa fue bastante novedosa y avanzó en la implementación de una serie de medidas que permiten garantizar los derechos de los trabajadores y proteger a las ERT. La Ley 26.684, como dice, Gebhardt (2011: 784) "tiene el especial designio de propulsar fuertemente las cooperativas de trabajadores como reemplazantes del empresario cesante, incapaz de obtener acuerdos que impidan su quiebra". El legislador no hizo más que volcar en la ley una serie de derechos y mecanismos destinados a salvaguardar los intereses de los trabajadores que quieren conservar su fuente laboral. La ley, pues, brinda en última instancia un homenaje al trabajo como bien humano básico.

Más allá del avance legislativo, todavía quedan cuestiones sin resolver. Uno de los principales problemas -que sólo queremos dejar planteadogira en torno a la expropiación de los inmuebles ${ }^{29}$. El instituto de la expropiación, propio del derecho público, le brinda al Estado la posibilidad de apropiarse, mediante el pago de una indemnización, de un bien particular ${ }^{30}$ por razones de utilidad pública ${ }^{31}$. Los trabajadores

29 Sobre la cuestión de la expropiación y las empresas recuperadas, ver Echaide (2007: 93 y ss), Tevez (2010: 203-217), Feser (2011), entre otros.

30 Así pues, la expropiación es ni más ni menos que una limitación a la propiedad privada, la cual según nuestra Carta Magna es inviolable. En efecto, el artículo 17 establece "La propiedad es inviolable, y ningún habitante de la Nación puede ser privado de ella, sino en virtud de sentencia fundada en ley". Sin embargo, los derechos no son absolutos, como en reiteradas oportunidades ha dicho la Corte Suprema de Justicia de la Nación (Fallos 136: 170; 304: 319 y 1524; 321: 3630). En este sentido, en el marco de la expropiación el interés particular es sacrificado por la satisfacción de un interés social superior. Esto, por cierto, no significa una anulación del interés particular. En efecto, como explica Ekmekdjian (1994: 210), la expropiación es un modo correcto de resolver con equidad un conflicto de intereses y "si bien 
han buscado continuamente la sanción de leyes de expropiación para adquirir de modo definitivo el inmueble de la empresa, luego de que el Estado realice la escritura correspondiente a favor de la cooperativa. Si bien existen leyes que han establecido la utilidad pública de varios inmuebles32, los procesos suelen encontrar muchas dificultades ${ }^{33}$.

No hace falta ir muy lejos en el tiempo para ver los problemas a los que se enfrentan las ERT. El 30 de noviembre de 2016 el Congreso de la Nación sancionó el Proyecto de Ley registrado bajo el $n^{\circ} 27.344$ que declaraba de utilidad pública y sujetos a expropiación los inmuebles y todas las instalaciones que componen el edificio del Hotel Baven. A pesar del avance que habían logrado los trabajadores, el 26 de diciembre el Presidente de la República Argentina vetó el proyecto y dejó sin efecto la ley mediante el decreto 1.302. El principal argumento que expuso fue que "el proceso expropiatorio implicaría un severo perjuicio en la posibilidad de asignar por parte del Poder Ejecutivo nacional los recursos económicos disponibles a otras necesidades básicas insatisfechas para el conjunto de la población, exclusivamente en beneficio de una situación particularizada que sólo afecta a un grupo de personas que se hallan comprometidas en las actividades que se desarrollan en el inmueble en cuestión". Como no podía ser de otra manera, los trabajadores no se quedaron en silencio y en la actualidad continúan con su lucha para obtener la expropiación. Como después del veto presidencial el proyecto vuelve al Congreso, deben conseguir el voto favorable de los dos tercios de cada cámara; de ser así el proyecto es ley y pasa al Poder Ejecutivo para su promulgación ${ }^{34}$.

\section{La naturaleza de las ERT y su papel en la construcción del Estado democrático de Derecho y el afianzamiento del derecho al trabajo}

El desarrollo que hemos realizado nos permite realizar algunas breyes reflexiones de carácter filosófico con respecto al movimiento populista de las ERT. Las últimas décadas de nuestro país han demostrado que las

prevalece -como es obvio- el interés general, el titular desapoderado tiene derecho a ser indemnizado por los perjuicios que tal privación le cause".

31 Al respecto, la Ley Nacional de Expropiación (Ley 21.499) dice que "La utilidad pública que debe servir de fundamento legal a la expropiación, comprende todos los casos en que se procure la satisfacción del bien común, sea éste de naturaleza material o espiritual". A los efectos de un mayor estudio de la ley, ver el comentario de Casas \& Romero Villanueva (2005).

32 Así por ejemplo, en la Ciudad Autónoma de Buenos Aires, la Ley 1.529 sancionada en el 2004 declara de utilidad pública a trece inmuebles ocupados por trabajadores con el fin de ser sujetos a expropiación.

33 Feser (2011: 57) explica que si bien hay "una tendencia lenta al cumplimiento por parte del Gobierno de la Ciudad, lo cierto es que aún a seis años de su sanción ninguna fue pagada por lo que aún no se ha producido la cesión a título oneroso necesaria para que comience a correr el plazo de pago por parte de las ERTs".

34 Artículo 83 de la Constitución Nacional. 
ERT se definen por su aptitud, su capacidad de creación y conquista en materia de derechos y satisfacción de intereses. Son, como todo movimiento popular, un movimiento de poder. Que sean poder, comprende dos significados que están relacionados: la posibilidad y la fuerza. En efecto, que algo pueda, significa que lo puede porque tiene fuerza; que algo tenga fuerza implica que la tiene porque es posible. En estos términos, las ERT están frente a múltiples caminos posibles por recorrer para alcanzar sus metas y pueden abrirse paso en ellos porque disponen de la fuerza necesaria para hacerlo. La idea de fuerza, por cierto, implica un doble movimiento: la fuerza afecta a otra fuerza que a su vez la afecta a aquella. Cualquier fuerza mantiene una relación esencial con otra fuerza. Así pues, las ERT son una fuerza que se expresa como un "nosotros, el pueblo" y que se enfrenta contra otra fuerza que la afecta: el "ellos-poder"35. Ese "nosotros, el pueblo", como explica Butler (2011), significa una autodesignación y autoconstitución que produce una reunión que se articula como "el pueblo". Es la expresión pura de la soberanía popular que comienza con una larga declaración de necesidades y reclamos frente a demandas insatisfechas.

Frente a las políticas económicas de ajuste, el incremento del desempleo y la concentración del capital en unas pocas manos, las ERT se expresan como un flujo de poder que en tanto fuerza y posibilidad inserta la novedad y establece un quiebre. Son una potencia revolucionaria que marca la diferencia y ofrece resistencia. Cuando esa potencia se actualiza da lugar a nuevas instituciones, derechos, conquistas. Muchas veces su potencial se cristaliza y queda homogeneizado en el sistema: en especial en leyes que representan sus victorias. Esto sucede, como hemos visto en detalle, con las modificaciones que se fueron introduciendo en la Ley de Concursos y Quiebras. Pero en ese proceso el movimiento deja su huella, la ruptura de su potencial creador. El sentido del movimiento de las ERT es colocarse como fuerza y posibilidad frente al modelo económico dominante del cual a su vez se distancia.

Las ERT son un actor político esencial en la construcción dé Estado democrático de derecho. En efecto, el Estado democrático de derecho está constituido por dos elementos básicos. En primer lugar, que el Estado sea democrático supone que las decisiones son expresión de la voluntad de los ciudadanos. En segundo lugar, que el Estado sea de derecho implica que la voluntad democrática se ajuste a un marco jurídico y no atente contra los derechos fundamentales del hombre ${ }^{36}$. En

35 El poder no se trata, pues, de una simple relación entre dominador y dominado. El poder, como dice Foucault (1992: 152) "tiene que ser analizado como algo que circula, o más bien, como algo que no funciona sino en cadena. No está nunca localizado aquí o allí, no está nunca en las manos de algunos".

36 El principio democrático, según el cual las leyes son expresión de la voluntad ilimitada de los ciudadanos, parece entrar en pugna con la idea de Estado de 
un Estado de derecho, pues, las decisiones están sujetas a la ley y su guía debe ser el respeto de los derechos fundamentales. Las ERT se mueven entre estos dos principios, es decir, como participes de las decisiones democráticas y como fuerza política que exige a través de reclamos y protestas que el Estado satisfaga sus derechos básicos.

En lo que refiere a la participación democrática, las ERT en sus comienzos expresaron su vOZ sobre todo mediante marchas, ocupación de los inmuebles, denuncias en los medios de comunicación y peticiones al Estado de que intervenga para paliar la situación miserable en la que habían quedado luego de que las empresas quebraran. La serie de conquistas que han obtenido en la ley y la jurisprudencia fue fruto en gran parte de esta actitud. Se puede decir, entonces, que los trabajadores se hicieron escuchar en especial a través de la protesta social y todavía siguen adoptando esta medida como forma de participación política para hacerse escuchar en el "foro público"37. La protesta, aunque es considerada por algunos como un acto repudiable e incluso criminal ${ }^{38}$, debe verse más bien como un medio de reclamo legítimo y justificado. En efecto, quien protesta es porque expone, por lo general, una situación de vulnerabilidad ante la sociedad que amerita ser tenida en cuenta por las autoridades públicas ${ }^{39}$. En una democracia todos tienen derecho a ser escuchados y cuando esto no se puede lograr mediante los medios convencionales, la protesta se erige como un vehículo adecuado para que los menos aventajados den a conocer en el campo público su voluntad. Es una forma de achicar la brecha que existe entre "democracia real" y "democracia imaginada". El Estado democrático es un proyecto que debe ser sostenido en el tiempo y se construye cada día por todos sus miembros. En ese proceso la satisfacción de los derechos debe ser lo más igualitaria posible $y$, por eso, frente a situaciones desiguales la protesta busca equilibrar la balanza. En este sentido, podemos decir, como sostiene Gargarella (2005: 19), que la protesta es el "primer derecho", ya que se erige como "el derecho a exigir la recuperación de los demás derechos".

derecho. Así pues, la expresión "Estado democrático de derecho" puede resultar paradójica. Al respecto, ver Habermas (2001).

37 En este sentido, vale destacar el valor especial que tiene la libertad de expresión. Al respecto, Gargarella (2005: 25) explica que "no es un derecho más sino, en todo caso, uno de los primeros y más importantes fundamentos de toda la estructura democrática".

38 Sobre el problema de la criminalización de la protesta, ver los trabajos reunidos por Bertoni (2010) y por Beade \& Vita (2015).

39 Así, Alegre (2005) sostiene que los movimientos de resistencia "pueden ser considerados como aportes para el mejoramiento a largo plazo del sistema político y jurídico, como una desafío desprolijo pero imprescindible al statu quo, como un invalorable aunque costoso llamado de atención sobre las injusticias estructurales con las que de otro modo estaríamos dispuestos a convivir como parte del paisaje social". 
La protesta de los trabajadores tiene una direccionalidad bien clara: la satisfacción del derecho al trabajo, reconocido en el artículo 14 de la Constitución Nacional. Esto nos conecta con el segundo principio sobre el cual se asienta el Estado de derecho: la ley como marco de las decisiones democráticas y el respeto de los derechos fundamentales como guía imprescindible. Al respecto, basta con decir que la lucha instalada por el movimiento de las ERT busca que el Estado satisfaga ese derecho básico consagrado en la carta de navegación del país, que cumpla con la obligación de promover los medios necesarios para garantizar que los trabajadores tengan un salario mínimo y suficiente que les permita llevar a cabo su plan de vida. Se trata, pues, de preservar la actividad vital del hombre ${ }^{40}$, que no se reduce a un simple medio para la satisfacción de necesidades, sino que se expresa como un fin constitutivo de la persona. No interesa aquí, claro está, que la vulneración del derecho no haya sido producida por la acción directa de los organismos gubernamentales. Si existe una situación en la cual un derecho fundamental se encuentra comprometido, el Estado debe intervenir; no puede dejar de actuar porque es su responsabilidad que sean garantizados en la mayor medida de las posibilidades jurídicas y fácticas. En un Estado de derecho, ya sea por comisión o por omisión, los derechos fundamentales no pueden verse cercenados.

\section{Conclusiones}

El estudio de Laclau acerca del populismo resulta imprescindible a la hora de comprender las identidades colectivas y populares de nuestra historia. En este sentido, hemos destacado en particular el rol de las ERT como actores políticos y movimientos de poder que surgen frente a la violación de ciertos derechos esenciales del hombre, en especial del derecho al trabajo durante la crisis del año 2001. Hemos visto también cómo este fenómeno, lejos de ser una desviación de lo político, forma parte de su propia esencia y constituye un engranaje central de la democracia y el fortalecimiento de los derechos humanos. En efecto, el Estado democrático de derecho es una empresa que se construye a partir de la participación de todas las voces en el espacio público. Así pues, la participación de los movimientos populares bajo la bandera del populismo, como dice Laclau (2005), "garantiza la democracia".

Pero ese tomar parte en los asuntos políticos no está falto de compromiso jurídico, sino que tiene un horizonte claro: salvaguardar derechos esenciales. La intervención ciudadana debe contribuir en la

40 Tomamos la expresión, como es evidente, del joven Marx. Hay que aclarar, sin embargo, que de acuerdo con Marx (2012 [1844]: 103 y ss.) en el sistema capitalista se produce un quiebre en la relación que mantiene el trabajador con el objeto de su trabajo, que impide que lo reconozca como propio. El producto del trabajo se le presenta como algo ajeno, una privación y una pérdida que lo invalida. 
toma de decisiones políticas cuyo marco sea la ley y esté guiada principalmente por el respeto de los derechos fundamentales. Esto es lo que hasta ahora, en la última década, han venido haciendo las ERT en materia de derechos laborales.

\section{Bibliografía}

Aboy Carlés, G. (2013) "De lo popular a lo populista o el incierto devenir de la plebs", en Aboy Carlés, G., Barros, S. \& Melo J. Las brechas del pueblo. Reflexiones sobre identidades populares y populismo, Buenos Aires: UNGS, pp. 17-40.

Alegre, M. (2005) "Protestas sociales: żviolación o reivindicación del derecho?, en Gargarella, R. (coord.) El derecho a resistir el derecho, España: Miño y Dávila, pp. 59-78.

Beade, G. \& Vita, L. (coords.) (2015) Criminalización de la protesta: la respuesta del Estado frente a los reclamos ciudadanos, Buenos Aires: Ad-Hoc.

Bertoni, E. A. (comp.) (2010) ¿Es legítima la criminalización de la protesta?: derecho penal y libertad de expresión en América Latina, Buenos Aires: Universidad de Palermo.

Butler, J. (2011) '“Nosotros, el pueblo'. Apuntes sobre la libertad de reunión", en Badiou, A. Bourdieu, P., et al., ¿̇Qué es un pueblo?, Buenos Aires: Eterna Cadencia, pp. 47-67.

Casas, J. A. \& Romero Villanueva, H. J. (2005) Expropiación: ley 21.499 comentada, anotada y concordada con las normas provinciales, Buenos Aires: Astrea.

Dasso, A. A. (1994) "Cramdown. La transferencia forzosa de la empresa insolvente (Proyecto de reformas a la Ley de Concursos y Quiebras)", La Ley, Tomo 1994-E, pp. 1227-1239.

Dussel, E. (2015) "Cinco tesis sobre el 'populismo"', en Filosofía del Sur. Descolonización y Transmodernidad, México: Akal, pp. 219-246.

Echaide, J. (2007) "Sobre lo político y lo jurídico: la batalla legal de las empresas recuperadas", Revista Idelcoop, vol. 34, n 176, pp. 82-102.

Ekmekdjian, M. A. (1995) Tratado de derecho constitucional, Tomo 2, Buenos Aires: Depalma.

Feser, M. E. \& Lazarini, V. M. (2011) "Reforma de la ley de concursos y quiebras: desafíos para las futuras empresas", Revista Idelcoop, vol. 38, $n^{\circ} 205$, pp. 284-294. 
Feser, M. E. (2011) "La expropiación como solución para las empresas recuperadas: análisis retrospectivo a seis años de la ley 1529", Revista Idelcoop, vol. 38, n² 202, pp. 46-60.

Foucault, M. (1992) Microfísica del poder, Madrid, La Piqueta.

Gargarella, R. (2005) El derecho a la protesta: el primer derecho, Buenos Aires: Ad-Hoc.

Gebhardt, M. (2011) "La reforma concursal sobre cooperativas de trabajo", La Ley, Tomo 2011-D, pp. 780-793.

Habermas, J. (2001) "El Estado democrático de Derecho. ¿̇una unión paradójica de principios contradictorios?", Anuario de Derechos Humanos, Núeva Época, pp. 435-457.

Heidegger, M. (2001) Introducción a la metafísica, Barcelona: Gedisa.

Laclau, E. (1986) Política e ideología en la teoría marxista: Capitalismo, fascismo, populismo, México: Siglo Veintiuno.

Laclau, E. (2005a) "El populismo garantiza la democracia", en Diario La Nación, 10 de julio de 2005. Disponible en http://www.lanacion.com.ar/719992-ernesto-laclau-el-populismogarantiza-la-democracia. Consultado en 27/07/2016.

Laclau, E. (2005b) La razón populista, Buenos Aires: F.C.E.

Laclau, E. (2005c) "Populism: What's in a Name?", en Panizza, F. (ed.) Populism and The Mirror of Democracy, Londres, pp. 32-49.

Marx, K. (2012 [1844]) "Manuscritos económicos-filosóficos", en Fromm, E. Marx y su concepto de hombre, México: F.C.E., pp. 96-201.

Mosso, G. (1998) El "cramdown" y otras novedades concursales, Buenos Aires: Rubinzal-Culzoni.

Retamozo, M. (2006) 'Reseña de la 'La razón populista' de Ernesto Laclau", Sociedad Hoy, n 10, pp. 225-229.

Ruggeri, A. (2009) "¿Qué es una Empresa Recuperada por sus trabajadores?" en Ruggeri, A. (comp.) Las empresas recuperadas: autogestión obrera en Argentina y América Latina, Buenos Aires: FFyL, pp. 13-19.

Soul, M. J., Maçaira, J. P., Guevara, et al. (2012) El mundo del trabajo en América Latina: tendencias y resistencias, Buenos Aires: Ciccus, Clacso.

Tevez, A. N. (2010) Empresas recuperadas y cooperativas de trabajo, Buenos Aires: Astrea.

Tévez, A. N. (2011) "La cooperativa de trabajo como continuadora de la empresa en quiebra", La Ley, Tomo 201 1-D, pp. 959-978.

Tropeano, D. (2012) "Comité de control del concurso preventivo. Incorporación de los trabajadores", La Ley, Tomo 2012-A, pp. 39-43. 
Vieta, M. (2009) "Las empresas recuperadas por sus trabajadores como cooperativas de trabajo", en en Ruggeri, A. (comp.) Las empresas recuperadas: autogestión obrera en Argentina y América Latina, Buenos Aires: FFyL, pp. 93-102.

Vítolo, D. R. (2011) "Los paradigmas en el Derecho Concursal argentino. De las Ordenanzas de Bilbao a la ley 26.684", La Ley, Tomo $2011-\mathrm{E}, \mathrm{pp}$. 956-978.

Zanatta, L. (2015) El populismo, Buenos Aires: Katz.

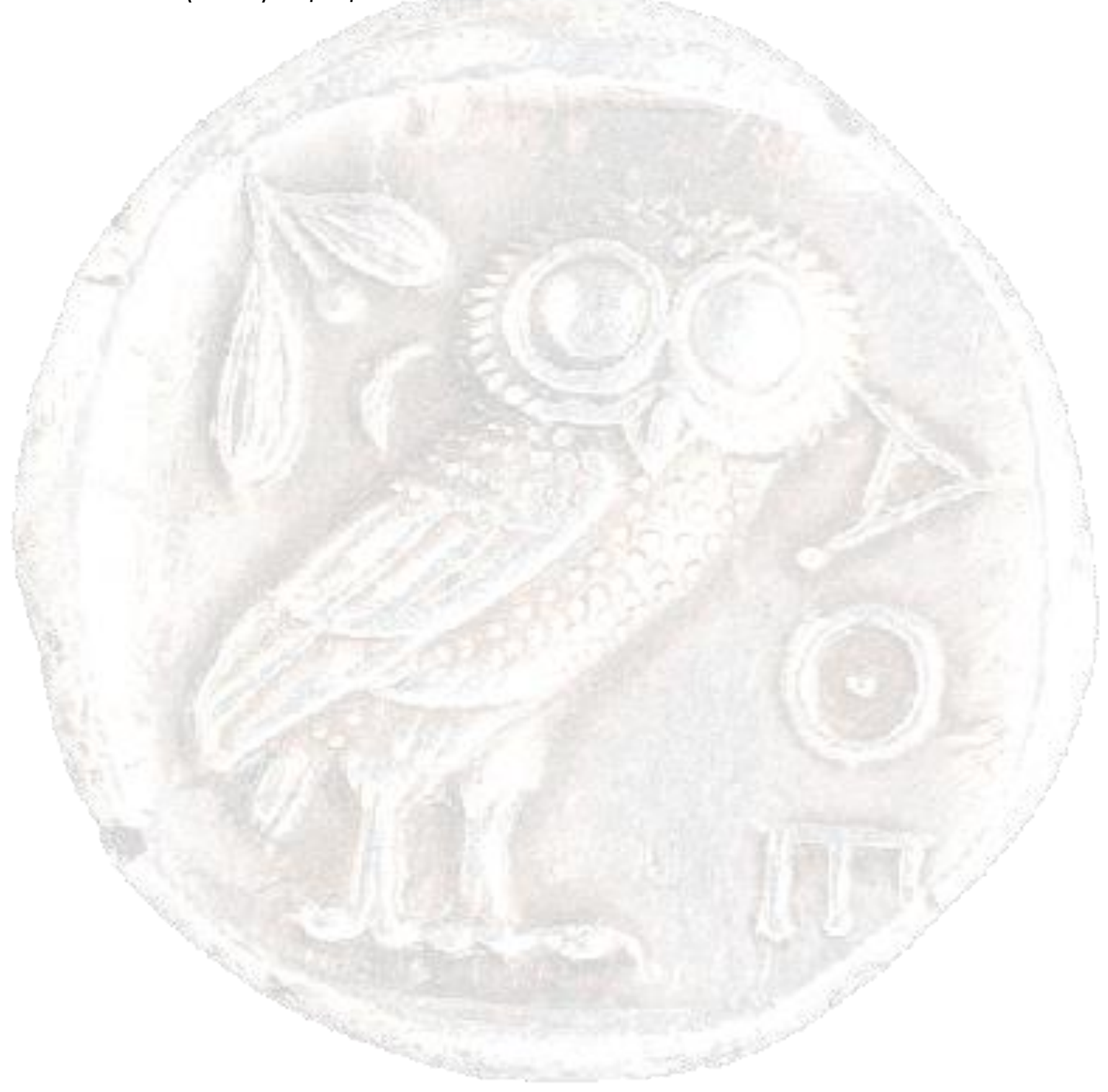

